\title{
Os intendentes "doutores" e a formação urbana de Campo Grande MT/MS (1905 - 1940)
}

The government "doctors" and the urban formation in Campo Grande MT/MS (19051940)

\section{Carlos Alexandre Barros Trubiliano}

Doutor em História

Professor Adjunto da Universidade Federal de Rondônia

trubiliano@hotmail.com

\begin{abstract}
Resumo: No início do século XX, a ferrovia Noroeste do Brasil promoveu profundas mudanças no sul de Mato Grosso. No campo político, a chegada dos trilhos propiciou a formação de uma nova elite política composta por representantes dos antigos criadores de gado e pelos chamados "doutores", profissionais liberais que para o local migraram em virtude dos atrativos político-econômicos decorrentes da ferrovia. O objetivo deste artigo é compreender como as políticas produzidas pela nova elite burocrático-intelectual de "doutores" equacionaram elementos do velho e do novo no processo de modernização e urbanização da cidade de Campo Grande. Tais políticas serviram para acomodar diferentes agentes sociais, bem como para manter sob controle os grupos marginalizados, tão comuns na fronteira Oeste.
\end{abstract}

Palavras-Chave: Doutores, Cidades, Urbanização, Modernização, República.

\begin{abstract}
In the beginning of twentieth century, Northwest of Brazil railway promoted profound changes in the south of Mato Grosso. Politically, the arrival of the rails caused the formation of a new political elite which consisted of representatives of old cattle farmers and so-called "doctors", professionals who migrated to the site because of political and economic attractive arising with railroad. This article aims to understand how the policies produced by the new bureaucratic and intellectual elite, called "doctors" equated elements of old and new in the modernization and urbanization process of the city of Campo Grande. Such policies have served to accommodate different social agents and to keep under control marginalized groups, so common on the western border.
\end{abstract}

Keywords: Doctors, Cities, Urbanization, Modernization, Republic. 


\section{Os doutores}

No início do século XX, o recém-instaurado regime republicano e a expansão da economia cafeeira em direção ao Oeste paulista e ao Sul de Mato Grosso provocaram profundas transformações na região; a principal delas foi a construção da Ferrovia Noroeste do Brasil (NOB). A NOB surgiu sob o signo da defesa do Estado Nacional e da expansão das relações capitalistas, ressignificou a dinâmica política local e transformou o espaço, provocando o aparecimento de cidades e impulsionando o crescimento de outras, como Campo Grande. Pelos trilhos chegavam ideias, mercadorias, informações e, principalmente, pessoas; os "forasteiros" causavam estranhamentos e conflitos, o surgimento e a afirmação de identidades.

Em meio a essas transformações, Campo Grande tornou-se, ainda no primeiro quartel do século XX, o principal centro econômico e político do Sul de Mato Grosso. Sua elite política era formada por homens cuja principal fonte de riqueza vinha da criação de gado: eram, essencialmente, fazendeiros - os típicos "coronéis", personalistas, clientelistas e patriarcalistas, descritos por Victor Nunes Leal em seu clássico Coronelismo, enxada e voto (1948). Para esses coronéis, a administração pública era uma continuidade da sede da fazenda. Com o passar do tempo, o desenvolvimento local e o crescente fluxo migratório, somaram-se a esse grupo os profissionais liberais advogados, engenheiros e médicos -, os chamados "doutores", que passaram a ocupar cargos públicos e a estreitar laços políticos e pessoais com os coronéis.

Os doutores identificavam-se, intimamente, com os comportamentos urbanos devido à sua formação acadêmica e à vivência nos maiores centros do país; os novos agentes sociais formaram uma geração de políticos diretamente responsáveis pela modernização de Campo Grande ao longo das décadas de 1920, 30 e 40. Nomes como Arnaldo Estevão de Figueiredo, Vespasiano Barbosa Martins, Arlindo de Andrade Gomes e Eduardo Olímpio Machado ocuparam importantes cargos na gestão estatal e na administração pública entre 1918 e 1941, e foram responsáveis pela consolidação do Plano de Alinhamento de Ruas e Praças e da modernização da infraestrutura urbana campo-grandense. Esses profissionais foram fruto da ampliação da oferta de cursos superiores no Brasil, nas primeiras décadas do século XX, fazendo com que estivessem "por toda parte médicos e advogados, cuja ilustração relativa, se reunida às qualidades de 
comando e dedicação, os habilitam à chefia. Mas esses mesmos doutores, ou são parentes ou afins, ou aliados políticos dos coronéis" (LEAL, 1984: 21-22).

O Brasil dos anos 1920-30 foi marcado pela expansão urbana, que acarretou profundas transformações sócio-espaciais: nem todos os chefes políticos municipais, a exemplo dos coronéis, eram grandes proprietários de terras. Profissionais liberais possuidores de relativa ilustração, carisma e capacidade de liderança tornaram-se chefes da política local; para além da carreira profissional, ser um doutor era "sinônimo de prestígio social, marca de poder político, se transformado em uma figura especial em meio a um país interessado em criar elites próprias de pensamento e direção política" (SCWHARCZ, 1993: 142).

$\mathrm{O}$ avanço do bacharelismo não significou uma força antagônica que sepultasse o coronelismo; pelo contrário, os jovens doutores constituíam uma nova geração capaz de revitalizar esse modelo político. Dotados de uma capacidade maior de persuasão, em virtude do melhor domínio das palavras e de uma maior simpatia popular - fruto das interações sociais estabelecidas com as práticas profissionais -, os doutores tornaram-se

os porta-vozes, os elementos intermediários entre as elites políticas locais e o executivo, na conquista de empregos e favores de cunho pessoal, bem como na defesa dos municípios que representavam no legislativo. De formação tipicamente urbana, ainda que vinculados à velha ordem, por relações de parentesco e amizade, não contavam os jovens doutores com uma força eleitoral própria. (...) Dos chefes políticos locais dependiam os votos que os reconduziam ou não ao Legislativo (SAMPAIO, 1975: 163-164).

Em Campo Grande, entre o segundo mandato do coronel Sebastião Lima (20/3/1918 a 5/9/1918) e a nomeação dos interventores pelo governo revolucionário de 1930, a cidade foi governada por nove intendentes - com destaque para os doutores Vespasiano Barbosa Martins, Rosário Congro, Arnaldo Estevão de Figueiredo, Arlindo de Andrade Gomes e Manoel Joaquim de Moraes. Respaldados no conhecimento técnicocientífico, esses gestores municipais empreenderam projetos e planos de intervenção sócio-espacial na cidade.

A gestão dos problemas urbanos pelos intendentes doutores cumpriu com a orientação republicana de que as municipalidades deveriam pautar suas políticas de urbanização nos parâmetros do higienismo, promovendo uma profilaxia social do espaço 
(CHALHOUB, 1996). O progresso via ordem justificaria as medidas comumente autoritárias tomadas pelos novos administradores - juristas, médicos e engenheiros.

A política republicana de estabelecer a ordem em nome do progresso difundiu a necessidade científica, social e moral de implantar projetos de urbanização que colocassem o país, predominantemente agrícola e rural, em sintonia com as capitais europeias. Em nome da modernidade, mesmo "as cidades portuárias mais movimentadas, mais modernas, mais europeizadas e os núcleos urbanos do interior que, na sua quase totalidade, viviam à margem da civilização, meras extensões das zonas rurais" (VIOTTI DA COSTA, 1994: 185), deveriam passar pelo processo de higienização e modernização do espaço.

Cientistas, médicos, sanitaristas e engenheiros foram convocados para iniciar campanhas higienistas, a princípio nas maiores cidades do país, a fim de solucionar o "caos urbano", fruto da crise habitacional que se agravava, das epidemias e dos problemas de saúde pública. A orientação era combater, se preciso pela violência, a desagradável presença de pobres e miseráveis nas ruas; erradicar as moradias coletivas; abrir avenidas e praças; melhorar a circulação do tráfego; e expandir a área urbana, transformando as cidades brasileiras em "cartões-postais da jovem e mal definida nação" (DOIN; PAZIANI \& CUELLO, 2006: 137).

O parecer técnico dos sanitaristas endossava a necessidade de intervenção do poder público no espaço e comportamento urbanos. A Paris haussmaniana ou a Londres vitoriana apresentavam-se como modelos de estabelecimento da violência física, fosse de forma real, pela demolição e expropriação de moradias populares e irregulares, ou de forma simbólica, por meio da "sutil violência repressiva, a penalidade incorporal e a sobriedade punitiva" (FOUCAULT, 1987: 47).

Campo Grande, durante os governos dos intendentes doutores, passou por diversos estímulos modernizadores: o aperfeiçoamento do aparato jurídico a partir da reformulação do Código de Posturas, em 1921; a regulamentação da inspeção e do abate do gado por meio da criação do serviço veterinário e do matadouro municipal; os melhoramentos nos serviços públicos, como a ampliação da iluminação pública, das redes de abastecimento de água encanada e do fornecimento de energia elétrica; o estabelecimento dos limites da zona urbana e rural; a normatização das construções e reformas prediais; o calçamento do centro comercial; e o nivelamento dos terrenos, medidas cujo objetivo era atribuir uma identidade progressista para a cidade. 


\section{Os Códigos de Posturas e o ordenamento social}

As diretrizes definidas no Seminário de Engenharia e Indústria, promovido pelo Club de Engenharia em janeiro de 1901, no Rio de Janeiro, influenciaram as ações de limpeza e embelezamento promovidas pelos agentes sociais de modernização nas cidades brasileiras (ROLNIK, 1997). Nos anais do Seminário, foram estabelecidos alguns preceitos para as construções nas cidades, como a adoção de recuos laterais e frontais entre os edifícios - fixados conforme altura e largura das edificações - e a instalação de janelas nas laterais dos prédios, medidas que priorizavam a ventilação e a incidência de luminosidade nos ambientes internos. Também foram estabelecidas as normas para a ocupação do solo; ressaltou-se a necessidade de analisar critérios como o relevo e as características climáticas, a fim de evitar áreas propícias à propagação de doenças.

O "casamento" entre medicina e engenharia promovia uma concepção de "ação regeneradora" sobre as cidades, com vistas ao controle das epidemias e às melhorias na salubridade. As normatizações do Club de Engenharia influenciaram as remodelações de urbes portuárias, como Rio de Janeiro e Santos, a construção de Belo Horizonte e das cidades que surgiram às margens das ferrovias, como Campo Grande e outras cidades do Sul de Mato Grosso e do Oeste de São Paulo.

Para os intendentes doutores, era necessário sofisticar a legislação urbana, especialmente os Códigos de Posturas, e implantar efetivamente as diretrizes do traçado do Plano de Alinhamento de Ruas e de Praças de Campo Grande.

Os casos dos Códigos de Posturas de Campo Grande, publicados em 1905 e 1921, não fogem aos ideais - republicanos e utópicos - de espaço higiênico físico e moral, onde fosse garantido o "bem-estar" social da população, bem como sua adequação a hábitos mais civilizados. A cidade, que nas primeiras décadas de século XX registrava crescimento econômico aliado ao populacional, buscou (re)configurar seu espaço urbano.

A importância crescente da cidade, como centro de comércio e de produção econômica e como sede do dispositivo central de poder político que intervém em todos os níveis da vida social, implica a construção de um funcionamento ordenado dos núcleos urbanos, condição de possibilidade da transformação dos próprios indivíduos e materialização da exigência normalizadora da nova ordem social (MACHADO, 1978: 260). 
O Código de Posturasteve por premissa o enquadramento da cidade a um projeto “civilizador”. Norbert Elias chama a atenção para as mudanças nos comportamentos humanos em direção à “civilidade”, como resultado do aprendizado social dos indivíduos, da reorganização dos relacionamentos humanos, do controle dos impulsos, do autodomínio e da auto-observação. Ainda segundo o autor, mesmo a "lavagem regular com sabão e água é outro desses 'atos compulsivos' cultivados em nossa sociedade pela natureza de nosso condicionamento e consolidados em nossa consciência por explicaçãode higiene, 'racionais"” (ELIAS, 1990: 267)

O primeiro Código de Posturas de Campo Grande, aprovado em 30 de janeiro de 1905, era uma cópia quase integral do Código de Posturas vigente na cidade de Corumbá, publicado em 1883 (OLIVEIRA NETO, 2003: 41). Em seus 12 capítulos e 54 artigos, a lei regulamentou comportamentos e fazeres cotidianos, abarcando padrões de higiene, limpeza e conservação dos espaços públicos, uma vez que

a organização da vida urbana, dentro de uma visão jurídica, pressupõe a formalização de padrões de comportamento que propiciem o convívio pacífico e ordenado dos homens. Para este sistema organizacional funcionar seria preciso estabelecer as formas, as regras e os limites das ações humanas (SILVA, 1997: 142).

Os espaços em construção na urbe tornavam difusa a fronteira entre o público e o privado. A exemplo do estudo de Ana Lúcia Duarte Lanna sobre as transformações urbanas na cidade de Santos, na passagem do século XIX para o XX, Campo Grande adotou, no mesmo período, "uma noção burguesa de família, moralidade e formação do indivíduo" (LANNA, 1993: 112) para definir os limites do público e do privado. O comportamento, agora, era de interesse do Estado e passou a ser regulamentado.

O Código de Posturas dedicou-se a educar as pessoas sobre os aspectos sociais e morais do comportamento: proibiu-as de dizer obscenidades, escrever e desenhar nas paredes das casas ou muros palavras ou figuras indecentes que ofendessem a moral pública. Não era permitido fazer barulho, algazarra e/ou gritar durante a noite, além de "fazer-se sambas, Catiretes, ou outros quaisquer brinquedos que produzam estrondo ou vozeria dentro da Villa” (CÓDIGO DE POSTURAS DE CAMPO GRANDE, 1905: art. 45), sob pena de multa de dez mil réis ou cinco dias de prisão. Observamos que essas regulamentações constavam em outros Códigos de Posturas de municipalidades 
brasileiras; por exemplo, o de Desterro (Florianópolis), que determinava, no art. 130, a proibição de: “ $\S 1^{\circ}$ Fazer bulhas ou vozeiras e $\S 2^{\circ}$ Fazer sambas ou batuques, quaisquer que sejam as denominações, dentro das ruas da cidade ou das povoações" (CÓDIGO DE POSTURAS DE DESTERRO, 1889: 25). A punição atingia, principalmente, as camadas mais pobres da população, coibindo suas manifestações culturais caracterizadas como "bárbaras" por uma elite que buscava se diferenciar dos "tipos populares", especialmente dos ex-escravos.

O porte de qualquer tipo de armas também era proibido, exceto por aqueles profissionais que delas necessitassem. A tentativa de evitar o porte de armas fazia parte do esforço para manter a ordem pública. Em última análise, a ideia era desarmar os cidadãos e as milícias, formadas por bandos de jagunços e controladas pelos grupos oligárquicos que travavam inúmeros conflitos armados pelo controle político, tanto de Campo Grande como do Estado. As disputas contribuíram para reforçar a imagem negativa de Mato Grosso, que passou a ser conhecido como "terra sem lei", ou terra em que a única lei existente era o "artigo 44" - ou seja, a lei executada com o "calibre 44" (PEREIRA, 1928:26). Contradizendo a perspectiva republicana de ordem e progresso, a cidade de Campo Grande e o estado de Mato Grosso emergiram no imaginário popular como o espaço da barbárie, em detrimento da civilização (GALETTI, 2000).

O Código de 1905 resultou do aprimoramento urbano de Campo Grande, imposto, sobretudo, pelas transformações que se anunciavam pela chegada dos trilhos da ferrovia. Com o progresso decorrente da estrada de ferro, a vinda de pessoas e a dinamização do acesso às mercadorias, o poder público da cidade empenhou-se em fazer com que os moradores de um vilarejo, formado por uma porção de ranchos, assimilassem elementos da nova sociabilidade em formação, marcada agora por espaços como ruas, praças, prédios e água encanada. Todavia, o Código de Posturas de 1905, enquanto instrumento civilizacional, pareceu ineficiente na visão das elites locais; foi necessário modernizá-lo, segundo o então intendente em 1921, Arlindo de Andrade Gomes:

O município possuía, desde 1906, um código que não cumpriu. Deficiente, ele foi modificado in limine por um sem-número de resoluções que se revogavam constantemente.

Assuntos de importância - higiene, construções, etc., etc., não estavam regulados. Em abril do ano passado, organizou a Câmara o Código de Posturas, que será distribuído ainda este mês. A importância da cidade com 
serviços iniciados, como passeios, calçamento, arborização, jardim, etc., reclamava uma legislação completa, que chegue ao conhecimento de cada habitante, limitando a ação individual, em benefício da ordem, da segurança dos bens públicos (GOMES, 1921: 48).

O novo Código de Posturas, dez vezes maior que o de 1905, continha 578 artigos divididos em 16 títulos. Lançado em 1921, suas principais preocupações eram o arruamento, a delimitação dos terrenos e o tipo de construções do centro da cidade. As questões sobre o comportamento social, presentes no Código de 1905, são reforçadas e a elas são incorporadas novas normativas. As diferenças básicas entre os dois Códigos são a sofisticação e a ênfase na urbanização da cidade, visíveis no de 1921 - o antecessor buscou, basicamente, regulamentar a conduta dos habitantes.

Devemos reforçar que ambos os documentos são frutos das demandas de seu tempo. Se o Código de Posturas de 1905 foi pensado para normatizar uma cidade de dois mil habitantes, o de 1921, sete anos após a chegada dos trilhos da NOB, buscava organizar a urbe cuja população registrava 21 mil citadinos ${ }^{1}$. No caso de Campo Grande, sua reformulação espacial sofre a interferência direta dos engenheiros militares e da ferrovia.

A expansão urbana ocasionada pelos trilhos, marcada por grande fluxo migratório, levou a elite local a fortalecer, a princípio, sua estrutura de dominação - "acomodando" os "forasteiros" que vieram para trabalhar na ferrovia e nas construções, ou os agricultores familiares que estavam em busca de seu "pedaço de chão" - para, posteriormente, definir os espaços de disputa de poder político.

Em 1909, o engenheiro Nilo Javari Barém foi contratado pela Intendência Municipal para elaborar uma planta de Campo Grande seguindo os interesses da ferrovia (um dos símbolos maiores da modernidade à época): a cidade passou a contar com o Plano de Alinhamento de Ruas e Praças (MACHADO, 1991). De acordo com o projeto, as ruas foram traçadas seguindo os pontos cardeais e ortogonais; as quadras formavam o desenho de xadrez. O objetivo era inserir a cidade no universo da vida civilizada, que continha elementos da racionalidade urbanística: a construção de ruas largas e de uma ampla avenida central ajardinada antevia o fluxo intenso de pessoas e mercadorias, e a edificação de uma praça central previa o núcleo da vida em sociedade (GARDIN, 1999).

\footnotetext{
${ }^{1}$ Dados obtidos no Instituto Brasileiro de Geografia e Estatística (1996) e Gilmar Arruda (1995: 32). O intenso crescimento populacional deve-se, sobretudo, ao advento da ferrovia Noroeste do Brasil.
} 
O espaço organizado sob a égide da ciência e da técnica procurava incorporar Campo Grande ao mundo moderno, introduzindo, na tradicional paisagem de "povoado de uma rua só", elementos urbanísticos convencionalmente chamados de operações de embelezamento e saneamento. Estas melhorias representavam outras relações entre os indivíduos e o espaço, marcadas por simbologias do urbano. A cidade passa a (re)afirmar, por meio de sua estrutura física e costumes em transformação, o modo de vida da urbeque buscava refutar, consequentemente, sua herança rural.

O Plano de Alinhamento de Ruas e Praças foi instrumentalizado e aperfeiçoado pelo Código de Posturas de 1921, também conhecido por Resolução n 43 . O Código de 1921 resultou do convênio firmado entre a Intendência Municipal e a Companhia Construtora de Santos que, à época, estava na cidade coordenando as obras dos quartéis militares. Até a década de 1920, os edifícios urbanos de Campo Grande localizavam-se entre o polígono dos córregos Prosa e Segredo. No entanto, a cidade crescia para além desses limites e era necessário organizar a expansão, sob pena de ali se repetir a desorganização contra a qual havia se implantado o Código de Posturas de 1905.

$\mathrm{O}$ intenso crescimento rumo ao norte do município deveu-se à chegada da ferrovia, em 1914; em direção ao Oeste, à instalação dos quartéis, entre 1921 e 1923. De acordo com o plano de expansão, a região Norte transformou-se em polo das atividades comerciais, concentrando na Rua 14 de Julho os principais estabelecimentos; a região Oeste tornou-se o espaço dos trabalhadores urbanos, com a implantação do primeiro bairro operário da cidade, o Amambaí.

O Código de Posturas de 1921 iniciou-se fixando os limites territoriais do município. A seguir, o conjunto de normas foi proposto em dois grandes eixos temáticos: a organização do espaço e a normatização do cotidiano.

O documento preocupou-se, sobretudo, em normatizar a construção e a expansão urbanas em Campo Grande. Dos 578 artigos, 255 eram dedicados a orientar a execução de obras privadas e/ou públicas, informando sobre registro de imóveis e terrenos, vistorias, embargos e multas; foram especificados a incidência do sol, da ventilação e da iluminação, a arquitetura de fachadas e o tamanho dos prédios, bem como os materiais utilizados nas obras.

O espaço urbano foi normatizado para garantir fluxo ininterrupto e veloz de pessoas e mercadorias, característica dos tempos modernos. A lei estabelecia: "a largura mínima das ruas é de vinte metros e das avenidas quarenta metros" (CÓDIGO DE POSTURAS, 1921: art. 7), não sendo permitida a “colocação de postes, arvores, cercas e 
obras que prejudiquem ao transito, nas vias públicas, para qualquer fim, sem consentimento da Intendência” (CÓDIDO DE POSTURAS, 1921: art. 9). A lei objetivou criar uma paisagem que representasse o status republicano de um novo tempo, de "um novo espaço, higiênico e grandioso, o que significa não colonial, limpo, varrido pela luz, visível para o controle, em suma, moderno" (ANDRADE\& MAGALHÃES, 1989: 53).

Maria Stella Brescianni afirma que, no início do século XX, a cidade moderna deveria ter "praças e jardins bem cuidados, ruas de traçado regular, amplas, arborizadas e iluminadas, cujo objetivo era evidenciar uma natureza domesticada e reelaborada para o prazer estético do homem" (BRESCIANNI, 1998: 239).Acerca do tema, Junia Marques Caldeira afirmou que, durante as primeiras décadas republicanas, a implantação das políticas sanitárias, com a instalação de infraestrutura e o embelezamento urbano nas cidades brasileiras,

(...) atingiu diretamente a estrutura dos espaços urbanos, modificando usos e costumes e gerando uma nova paisagem: a rua transformou-se no espaço do deslocamento, da velocidade, da circulação de pessoas, de mercadoria e de notícias; mercados, quiosques, e ambulantes passaram a disputar com lojas e galerias, a concorrência comercial (2007: 128).

Ainda segundo Caldeira, a política de ajardinamento empreendido nas cidades brasileiras durante a República Velha baseava-se em dois critérios fundamentais da urbanística moderna: o caráter funcional sanitarista e os aspectos estéticos que deixassem em evidência a beleza da flora brasileira.

O projeto de remodelação urbana em Campo Grande valorizou o verde da paisagem. Logo, o art. 46 das Posturas de 1921 previa que a arborização das avenidas e praças seria "feita de acordo com a planta aprovada pelo Intendente" (CÓDIDO DE POSTURAS, 1921: art. 46). Além do clima e da salubridade, Campo Grande é uma cidade muito quente e a sombra das árvores atenua a sensação térmica, cremos que outros fatores influenciaram a arborização da cidade. ${ }^{2}$

\footnotetext{
${ }^{2}$ Segundo Lucas Pestana, Flávio Alves e Ângela Sartori (2011: 01-21), Campo Grande é uma das cidades mais arborizadas do Brasil, apresentando um índice de cobertura vegetal de $74 \mathrm{~m}^{2}$ por habitante, enquanto o valor mínimo recomendado pela Sociedade Brasileira de Arborização Urbana (SBAU) é de $15 \mathrm{~m}^{2}$ por habitante.
} 
Sabe-se que o intendente Arlindo de Andrade Gomes interessava-se por Botânica, disciplina que lecionou por dois anos no Liceu Cuiabano. ${ }^{3}$ Destacamos que o planejamento da cidade era subsidiado por orientações relacionadas ao contexto histórico, porém fortemente impactado pelas preferências dos agentes locais.

A cidade que se pretendia moderna, limpa, organizada e ordenada não toleraria construções rústicas. O Código de Posturas determinou que os donos das construções de taipa, na área urbana central de Campo Grande, demolissem seus imóveis em cumprimento às condições de salubridade e de higiene impostas pela lei.

A intenção era a de construir um novo tipo de moradia para um novo tipo de morador. As casas de taipa, por exemplo, não poderiam ser mais reformadas e as fachadas de zinco ou tábua deveriam ser trocadas por tijolos. Os mais atingidos consequentemente seriam os mais pobres, cujas casas não poderiam seguir as especificações dos Códigos de Posturas. Mais um resultado do “drama do progresso" (ARRUDA, 1995: s.p.).

No entanto, houve aqueles que não se adequaram imediatamente à nova lógica organizacional de Campo Grande. Para a elite local que ambicionava uma cidade com o status de espaço civilizado e higiênico, era impensável que houvesse no centro da cidade, "coração" da zona comercial, "na confluência da Av. Afonso Pena com a Rua 14, onde hoje se eleva o Edifício Santa Olinda, (...) uma casa, velha, de pau-a-pique, chão batido, abaixo do nível da rua". Para Arlindo de Andrade, a permanência desse tipo de moradia era "uma agressão à físionomia da cidade" (SERRA, 1989: 09). A solução foi determinar “aos Irmãos Suarez, seus proprietários, que a demolissem” (SERRA, 1989: 09).

No entanto, os irmãos Suarez, "por turra ou estribados em direito, eles não a derribaram". A Intendência resolveu a questão por outros caminhos: “certa noite, em meados de 1923, dez ou mais homens, de machados e picaretas, puseram-na abaixo. De manhã, era apenas um monte de barro, taquaras e telhas velhas" (SERRA, 1989: 09).

A história não registra se a "derrubada" ocorreu na presença dos proprietários ou se foi precedida de vigilância, para aguardar a ausência dos mesmos. De qualquer modo, o fato é que o episódio é conhecido apenas pela destruição do imóvel, o que, por si só, exemplifica que o poder público não se importava com o destino dessas pessoas. Para o

\footnotetext{
${ }^{3}$ Entre 1908, quando chegou a Mato Grosso, e 1910, quando foi nomeado juiz de Direito da Comarca de Nioaque, Arlindo de Andrade Gomes foi professor de Botânica no Liceu Cuiabano (ANDRADE FILHO, 2000).
} 
intendente, aliás, se os mesmos desaparecessem do convívio social, seriam apenas dois indesejáveis a menos. A ação da Intendência é reveladora, porque representava, de"um lado, a ideia do progresso pela ciência" que prometia democracia e, por outro, atitudes arbitrárias tomadas em nome do desenvolvimento (CARVALHO, 1997: 35).

A tipificação de "forasteiros" em que se enquadram os irmãos Suarez é outro ponto que chama a atenção. Segundo Paulo Coelho Machado, os espanhóis Manoel e Izidro Suarez adquiriram, em 1915, o Hotel Globo, “a mais confortável hospedaria da vila de Campo Grande, procurada por boiadeiros, fazendeiros, políticos e homens de negócios" (MACHADO, 2000: 368). Ainda segundo o memorialista, na década de 1920, os Suarez tiveram outro atrito com a Intendência de Arlindo de Andrade Gomes quanto à venda dos terrenos para a construção dos quartéis em Campo Grande: “Arlindo tentou comprar terreno dos mesmos donos (irmãos Suarez) para a construção dos quartéis do Bairro Amambaí. Houve recusa e consequentemente desapropriação, numa demanda complicada em que a prefeitura saiu vencedora” (MACHADO, 2000: 150).

Os Suarez, "forasteiros" que "chegaram pelos trilhos" a Campo Grande, foram tipificados como "investidores"; portanto, sua presença também era considerada perigosa - uma vez que, possivelmente, filiaram-se a algum grupo político da cidade que fazia oposição ao intendente. O resultado da pendenga foi a desapropriação dos terrenos dos espanhóis em prol do bem público.

As medidas tomadas pela Intendência com o intuito de "limpar" ou embelezar a urbe relacionavam-se à infraestrutura, possuíam caráter punitivo e, por isso mesmo, educativo. A visão da casa dos Suarez, destruída na manhã que se sucedeu aos fatos, certamente alarmou a população para o perigo de desrespeitar o estabelecido pelas elites locais e, porque não dizer, compartilhado pelo campo-grandense. Contra os "pausrodados" ${ }^{\prime 4}$, de que os Suarez eram exemplo, a picareta seria usada, caso necessário. A demolição das casas de taipa era parte do processo de intervenção da Intendência e gerou a (re)significação social do território.

A dinâmica de interação entre os novos códigos e símbolos passou a comunicar aos citadinos um novo contexto de comportamento e ocupação em relação ao espaço. $\mathrm{O}$ embelezamento da cidade afastou, compulsoriamente, os populares do centro, paisagem a qual "enfeavam". Aos pobres, restou ocupar a periferia da cidade, seja o bairro popular

\footnotetext{
${ }^{4}$ Expressão popular utilizada no Mato Grosso para identificar o imigrante originário de outro estado ou país, geralmente "visto" com desconfiança pelas elites locais. Mais informações, ver, entre outros: GOMES, 2000.
} 
ou a zona rural. É importante ressaltar que a periferia, com o crescimento da cidade ao longo dos anos, transforma-se em parte do centro. Enfim, coube à Intendência educar a população residente na zona rural para as novas formas de sociabilidade, mais condizentes com o espaço urbanizado.

Os pressupostos de civilidade que conformam o urbano também deveriam compor o universo rural. A "vida rústica da roça", mesmo sem infraestrutura, equipamentos, serviços e bens de consumo da cidade, não poderia prescindir dos ideais de civilização.

O Código de 1921, em seu $8^{\circ}$ Título ("Das roças, queimadas e cercas”), imputou deveres aos moradores da zona rural (construção e manutenção de cercas), regulamentou a passagem de estradas públicas e caminhos pelas propriedades, proibiu queimadas nas roças, bem como exigiu cuidados para que "carneiros, cabras, porcos, galinhas e cães" não causassem prejuízos aos vizinhos; a pena, se houvesse acordo, era a entrega do animal como forma de pagamento pelos danos (CÓDIGO DE POSTURAS, 1921: art. 291).

O artigo 284 merece leitura mais atenta: "Nos limites do Município, é proibida a derrubada de mata virgem, para roças e lavouras. Multa de cinquenta mil reis (50\$000)". Para Eduardo Taveira e Maria Inês Higuchi, a construção de políticas públicas ambientais voltadas à disciplina dos cidadãos e de seu entorno transforma lugares em espaços ambientalizados, permitindo "delimitações administrativas onde os espaços podem ser desorganizados, recombinados e submetidos ao desenho disciplinar dos especialistas em gerenciamento" (TAVEIRA\&HIGUCHI, 2011: 54).

A (re)organização da zona rural em Campo Grande pretendia fazer com que "a roça ficasse na roça", mas o cotidiano da cidade era marcado pela presença de animais e ambulantes, "carroceiros" que vendiam de "porta em porta" os produtos de suas plantações. Logo, para uma cidade que pretendia ascender ao status de espaço moderno, esse tipo de prática não seria conveniente. Deste modo, no $10^{\circ}$ Título ("Da polícia administrativa"), o Código buscava proibir a passagem de "tropas e boiadas pelas ruas" (CÓDIGO DE POSTURAS, 1921: art. 303, § 10) do município fora do horário estipulado (depois das cinco da manhã, ou antes da meia-noite), e as vendas dos pequenos produtores fora do espaço da feira municipal.

O Código de 1921 buscou organizar a ocupação do espaço rural e urbano. Contudo, foi durante a Intendência de Eduardo Olimpio Machado, através da Lei n. 24, de 02 de dezembro de 1937, que se definiram os marcos limítrofes dos distritos, das zonas urbana, suburbana e rural de Campo Grande, ficando assim estabelecido: 


\section{Zona Urbana}

Partindo do limite da fazenda Bandeira, no bairro Amanbahy, com terrenos do 18 B.C.; daí até a estrada de Ferro Noroeste por esta até o prolongamento da avenida Mato Grosso (...)

Zona Suburbana

Partindo do cruzamento da linha do patrimônio com a nascente do córrego Neco Dias subindo por este até sua barra no Córrego Segredo(...)

Zona Rural

Área compreendida entre os limites das zonas suburbana e as raias do Patrimônio Municipal, conforme planta oficial (CAMPO GRANDE, 1937: 09-11).

Com a definição das zonas da cidade, a Lei n.24, em seu art. 25, deliberou sobre a cobrança de imposto predial para as edificações no perímetro urbano, designou fiscais municipais, determinou multas e a data limite do primeiro dia útil de cada mês para o pagamento dos tributos. A legislação ainda definia as prerrogativas sobre os mercadores ambulantes, que deveriam portar licença em dia, sob pena de apreensão de mercadorias restituídas somente após a quitação do débito, acrescido de multa que variava entre $20 \$ 000$ a $50 \$ 000$.

Nas primeiras décadas do século $\mathrm{XX}$, as camadas mais populares atuavam como vendedores ambulantes, comercializando pelas ruas os mais variados produtos, majoritariamente gêneros alimentícios. Quitandeiras, verdureiros, leiteiros, peixeiros e vendedores de carnes, aves e miúdos passavam a compor, cada vez mais, o cenário urbano campo-grandense, constituindo com os empórios, mercados, vendas de secos e molhados e armazéns um importante elo entre os produtores rurais e os consumidores na cidade.

A relação da Intendência com os vendedores ambulantes foi conflituosa. A institucionalização de normativas - previstas nos dois Códigos de Posturas e em leis “avulsas" - sobre a forma de produção, armazenamento, higiene e comercialização desses produtos procurava oferecer melhores condições de consumo aos habitantes, ao mesmo tempo em que se instituía um cerceamento a esses comerciantes, controlando e limitando seus movimentos.

O trabalho de verdureiros, quitandeiras, leiteiros e tripeiros era útil ao abastecimento da cidade. Conduto, para o pensamento urbanista e sanitarista, esse tipo de comércio representava um entrave para a livre circulação - já que, não raro, muitos desses comerciantes montavam suas barracas nas calçadas - e uma potencial ameaça à 
salubridade urbana, com a venda de carne, leite, ovos, peixes e frutas estragadas, em virtude das precárias condições de armazenamento e transporte ou do vencimento de sua validade. Em síntese, o ambulante contrariava o ideal da cidade moderna, bela, higiênica e saudável.

Em decorrência do processo de estruturação urbana, da chegada pelos trilhos de um número cada vez maior de imigrantes e a necessidade de novos hábitos de consumo, os intendentes doutores - tributários dos novos tempos, "tempos civilizados" - tomaram medidas para organizar o espaço e assentar esses novos agentes. Nesse período, além de normatizações cada vez mais específicas para venda e produção de gêneros de primeira necessidade, são criadas colônias agrícolas e a feira livre, ambiente destinado para viabilizar o contato direto entre produtores e consumidores e concentrar o comércio de frutas, hortaliças, ovos, peixes e carnes, tornando possível uma vigilância sanitária mais eficiente.

Impulsionada pelo crescimento populacional, e como parte da política para assentar os imigrantes e ocupar os "espaços vazios", a gestão de Arlindo de Andrade Gomes incentivou a criação de colônias agrícolas nos Distritos de Terenos, Jaraguari e Rio Pardo. Por meio da doação de terras, pequenos agricultores, sobretudo colonos europeus e japoneses egressos das lavouras cafeeiras de São Paulo, foram estimulados a fixar-se nesses distritos. Eles chegaram a Campo Grande empregados na construção da linha férrea da Noroeste do Brasil, e passaram a se dedicar "nas redondezas da cidade, à pequena agricultura, abastecendo diariamente o mercado consumidor" (CONGRO, 1919: 38).

A formação das colônias agrícolas não extinguiu a prática popular de cultivar, em suas propriedades, pomares e pequenas hortas. Contudo, como parte da urbanização e da criação de um "cinturão verde" nos arredores da cidade, cresce o comércio de gêneros alimentícios e a necessidade de se criar um espaço específico para comercializá-los. Durante a Intendência de Arnaldo Estevão de Figueiredo (1924 a 1926), por meio do Ato n.17, de 4 de abril de 1925, a feira livre foi instituída no pátio do atual Mercado Municipal. Seu funcionamento às quintas-feiras e aos domingos, das $5 \mathrm{~h}$ às $9 \mathrm{~h} 30 \mathrm{~min}$, tornou-se “ponto obrigatório da presença de meio Campo Grande (sic)" (LEITÃO, 1939: 68).

Em suas memórias, Figueiredo nos fornece pistas do esforço do poder público para estabelecer a feira e os colonos: 
Demos total assistência técnica para a produção, os colonos traziam, nos finsde-semana, carroças e mais carroças para a cidade com os produtos plantados, a fim de serem comercializados na feira livre, que foi inaugurada em minha administração municipal. A princípio não havia, para ela, lugar certo. Funcionava em ruas, avenidas até que se fixou no lugar do atual Mercado Municipal e o prestimoso Antônio Valente a administrava gratuitamente (RIBEIRO, 1993: 305).

A formação das colônias agrícolas fez parte do esforço político de (re)organização do território, articulada com o processo de desapropriação de pequenos produtores em áreas próximas ao perímetro urbano da cidade. Deste modo, as colônias acomodaram, no entorno da cidade, os desapropriados, assim como parte das levas de migrantes que chegavam pelos trilhos.

Além das demolições, desapropriações e construções promovidas pela Intendência e que "transformavam" o espaço em Campo Grande, destacamos que o Código de 1921, assim com seu antecessor, pretendia modificar os costumes e comportamentos dos moradores. Era necessário incutir nos citadinos, especialmente nos populares, novos modos de viver e conviver, mais adequados à cidade que se modernizava. Para tanto, foram criadas, ou aprimoradas a partir das Posturas de 1905, ordens e proibições que atingiam diretamente os hábitos, o convívio, os modos de lazer e de sobrevivência dos habitantes.

Enquanto o primeiro Código objetivava instituir um ordenamento nas práticas espaciais da cidade, as Posturas de 1921 iam além e pretendiam consolidar os preceitos de urbanidade em voga nos principais centros do país à época: alinhamento reto, cuidados especiais com a salubridade, institucionalização e operacionalização do comportamento higiênico e do espaço produtivo. A política, em sintonia com o governo republicano, atendia aos anseios das elites brasileiras, para as quais

os rebeldes, os imigrantes, os trabalhadores que resistiam ou se opunham eram classificados como incapazes e ignorantes, pois não sabiam reconhecer "os benefícios da civilização". Eram, consequentemente, bárbaros e, quando se manifestavam, perigosos. "A questão social é uma questão de polícia” (...). Em outras palavras, na medida em que havia resistência ao projeto e que as "classes perigosas" demonstravam muito bem saber que determinados 
"benefícios da civilização" não eram para todos, a política foi a repressão (NETO, 2003: 227).

Algumas das normatizações estavam reunidas no título Da policia administrativa, dividido em dois capítulos. O primeiro tratava "Dos costumes públicos e medidas de segurança"; o segundo, "Dos divertimentos públicos". Para fiscalizar, foi criada a Polícia Administrativa, composta por funcionários da Intendência cuja atribuição era observar o cumprimento das Posturas, emitir multas e intimações. Para as detenções previstas pelo Código, a Polícia Civil era acionada.

Nos dois capítulos, várias normativas regulamentadas em1905 são reforçadas: aferição e regulação das balanças, padronização de pesos e medidas, proibição de falar e escrever obscenidades em espaço público e estabelecimento de regras de higiene para bares e restaurantes. Questões como a prática esportiva, a mendicância, a comercialização e o consumo de bebidas alcoólicas e os jogos de azar passaram a ser regulamentadas.

Os esforços para construir uma nova cidade, habitada por pessoas com novos comportamentos, passou pela regulamentação das atividades esportivas, especialmente do futebol. Pelo Código de 1921, especialmente no art.304, estavam proibidos, sob pena de multa de cinquenta mil réis, os jogos de "futebol com bolas ou qualquer espécie nas ruas, praças, largos, logradouros e passeios, bem como quaisquer outros jogos ou divertimentos que pudessem embaraçar o trânsito, prejudicar os habitantes ou os prédios" (CÓDIGO DE POSTURAS, 1921: 304).

À época, a proibição da prática do futebol em vias públicas também ocorreu em outras cidades brasileiras, a exemplo de Salvador (BA). Henrique Sena dos Santos, em sua pesquisa de mestrado, observou a classificação do esporte pelas elites soteropolitanas por meio da imprensa - "foot-ball de vadios", "foot-ball de vagabundos", "foot-ball nocivo" e "foot-ball prejudicial" -, que tipificava os jogadores como "moleques de rua", “desordeiros", “vadios" e "peraltas” (SANTOS, 2012:75).

A lei atingia, portanto, os setores populares da cidade que buscavam o futebol como diversãoe prática desportiva, já que a elite campo-grandense reunia-se no clube social da cidade, o Rádio Clube, ambiente privado para a prática de esportes, sugerido como mais adequado pelas Posturas. Não por outra razão, com o tempo, clubes populares, embora privados, foram aparecendo na cidade, evidenciando, mais uma vez, o caráter educativo da legislação municipal. 
O destaque para o futebol deve-se à difusão do esporte entre os trabalhadores das cidades, já em fins do século XIX. Conforme Eric Hobsbawm, o futebol tornou-se, à época, uma espécie de "religião leiga da classe operária" (1987: 262) e, em curtíssimo espaço de tempo, de "toda a população trabalhadora do mundo" (SEVCENKO, 1994: 35). Isso porque os trabalhadores encontraram no esporte as novas bases emocionais de coesão, identidade e solidariedade coletiva, substituindo as comunidades e os laços de parentesco que cada um deixou ao emigrar para as cidades. No entanto, a prática do futebol exigia espaço. Logo, o Código de Posturas de 1921, ao restringir ao clube o espaço do jogo - um ambiente fechado, vigiado e selecionado -, buscou controlar o cotidiano dos operários.

A mendicância, assim como o futebol, era prática nociva ao ambiente público. Sobre o tema, o art. 319 estabeleceu: "É proibido mendigar pelas ruas e praças da cidade, povoações e estradas públicas do município, sem estar munido de atestado médico de invalidez e atestado de indigente passado pela autoridade policial e vistados pelo intendente (...). Os infratores serão detidos e entregues a polícia" (CÓDIGO DE POSTURAS, 1921: art. 319). Como no caso do futebol, a prática legal da mendicância não era proibida, mas tornava-se inviável diante da burocratização.

Por meio desse aparato legal, a Intendência buscava diferenciar os "mendigos" dos "andarilhos", já que ambos passavam a compor a paisagem humana campograndense, especialmente após a chegada dos trilhos. Os mendigos eram considerados afeitos à violência: a ideia geral era a de que eles permaneciam na cidade até o ponto em que não conseguiam benefícios oriundos das esmolas, do roubo, da bebida e de pequenos favores. Os mendigos eram, normalmente, indivíduos conhecidos da população. Já os andarilhos eram classificados como seres anônimos que não permaneciam no lugar, embora, no imaginário social, eles representassem o medo, estimulado pela fantasia de figuras presentes em várias regiões do país, como a "cigana" ou o "homem do saco"5, "aquele que vinha buscar crianças que eram desobedientes" (SANTOS, 2011: 30).

Deve-se registrar, entretanto, que as figuras do mendigo, do andarilho e inclusive a dos trabalhadores da urbe representavam, simultaneamente, o arcaico e o moderno. Os

\footnotetext{
${ }^{5}$ Gilberto Freyre (1988: 368), em Casa Grande \& Senzala, faz referência ao homem do saco que se alimentava de "fígado de menino". Monteiro Lobato também faz referência ao Papa-Figo ou homem do saco: "Com seu saco cheio de brinquedos velhos e latas, lá vem o Papa-Figo, um sujeito sujo, barbudo e maltrapilho que está sempre rondando escolas, parques e jardins. Para atrair as crianças, oferece os brinquedos que traz no saco, mas depois devora o fígado dos pequeninos. Conhecido no sudeste do Brasil, também é chamado de homem do saco" (2003: 18).
} 
operários são necessários e bem vistos, desde que não ostentem comportamentos considerados incivilizados - como, aliás, tendiam a fazer na visão da elite que, por isso mesmo, tentava educá-los para viver na cidade, sem conscientizá-los das possibilidades políticas que de fato representavam em um regime republicano. ${ }^{6}$ Parece-nos que as reformas e as leis não impediram que os pedintes e os trabalhadores pobres, empurrados para zonas periféricas, circulassem pelo centro político-econômico do município e transformassem os espaços urbanos. Esses novos personagens urbanos, considerados "efeitos colaterais" do progresso, reinventavam os sentidos da modernidade desejada, contrapondo-se aos belos edifícios, praças e jardins.

Em relação ao combate promovido pela Intendência às práticas sociais "incômodas", fazemos referência aos artigos 306 e 309 que regulamentavam, respectivamente, a venda de bebidas alcoólicas e a proibição dos jogos "maléficos" à sociedade. Os estabelecimentos comerciais ou clubes que vendessem "bebidas alcoólicas a pessoas embriagadas" e/ou permitissem "os jogos de azar e parada"7 estavam sujeitos à pena de vinte mil réis e cassação das licenças. Ainda quanto à regulamentação da venda de bebidas, parece-nos que o Código buscava combater os consumidores que andavam de "bar em bar", embriagados pelas ruas da cidade, "incomodando" os transeuntes; este comportamento era identificado nos populares, já que as senhoras e senhores respeitosos “dos bons costumes" tornavam o bar um espaço privado no avançado das horas, exigindo do comerciante que fechasse o estabelecimento ao público e que os atendesse com exclusividade.

Em Campo Grande, o jogo contava com uma estrutura considerável na década de 1920. Segundo Ulisses Serra, na cidade

se podia jogar até a meia-noite, mas em verdade se jogava a noite toda e em grande parte do dia.(...). O Líder e o Tênis eram excelentes clubes. (...) com foros de cassino, dotado de salões, salas e alpendres e restaurantes, quase suntuoso, o Recreativo, dos irmãos Gazal, Miguel, Manuel e Nicola. Até

\footnotetext{
${ }^{6}$ A ordenação do espaço é fruto dos antagonismos da sociedade capitalista. Logo, as construções de bairros operários surgiram como parte do processo de modernização urbana no Ocidente. Para o capitalismo, o operário é necessário, mas ao mesmo tempo "indesejável” pelo seu comportamento considerado "nocivo" à ordem social. Desde o século XIX, nas cidades que se industrializavam, buscou-se demarcar o espaço dos diversos agentes sociais que as compunham, segundo Frederich Engels (1985), ao descrever as condições de vida do proletariado urbano nos bairros operários de Manchester, em 1845.

${ }^{7} \mathrm{O}$ termo "jogos de parada" é usado, em algumas regiões do país, para definir jogos que se utilizam do carteado, como o Lansquenet e o Bacará, ou de cartões numerados como a Víspora ou Bingo, como podemos constatar nos trabalhos de MAIA, 2001; SANTOS, 2002; SELBACH, 2009.
} 
durante o dia, da rua ouvia-se o tilintar das fichas de madrepérola, caras e vistosas, misturado à voz dos crupiês insaciáveis, que pediam jogo! Mais jogo! (1989: 49).

Ao que tudo indica, o combate ao jogo ocorreu em Campo Grande por campanha do governo estadual, uma vez que só "no primeiro período governamental do Dr. Mário Correia da Costa", governador de Mato Grosso de 1926 até 1930, "foi desencadeada uma forte campanha repressiva. Fecharam-se todas as casas de tavolagem" (SERRA, 1989: 50). Em relação ao governo federal, somente em 1946, por meio do Decreto-Lei n.9.215, de 30 de abril, assinado pelo Presidente Eurico Gaspar Dutra, é que os jogos de azar passaram a ser proibidos em território nacional.

Entendemos que esse conjunto de leis e de reformas em Campo Grande, nas primeiras décadas do século XX, significou um processo dramático de transformação dos hábitos cotidianos dos indivíduos, atendendo a um projeto de reajustamento ou aburguesamento social, em sintonia com o regime republicano. Não apenas em Campo Grande, mas também em outras cidades brasileiras, a transformação do espaço público, do modo de vida e da mentalidade dos moradores atendeu, segundo Nicolau Sevcenko ao analisar o caso da cidade do Rio de Janeiro, a

Quatro princípios fundamentais [que] regeram o transcurso dessa metamorfose, (...) a condenação dos hábitos e costumes ligados pela memória à sociedade tradicional; a negação de todo e qualquer elemento de cultura popular que pudesse macular a imagem civilizada da sociedade dominante; uma política rigorosa de expulsão dos grupos populares da área central da cidade, que será praticamente isolada para desfrute exclusivo das camadas aburguesadas; e um cosmopolitismo agressivo, profundamente identificado com a vida parisiense (1983:30).

Os Códigos de Posturas surgiram em Campo Grande como resultado de uma nova sociabilidade, expressa em diversas ações das autoridades públicas voltadas à remodelação do espaço urbano. Esse novo contexto político, marcado pelo fortalecimento do Estado republicano, seria o elemento principal a determinar a produção espacial e social do lugar. É bem verdade que as mudanças dos costumes e valores culturalmente enraizados foram lentas e parciais, obviamente definidas pelo tempo e pela História 
(THOMPSON, 1998). Entretanto, devemos considerar que, por meio das leis, as elites buscam

(...) organiza(r), classifica(r) e coleciona(r) os territórios urbanos, conferindo significados e gerando noções de civilidade e cidadania diretamente correspondentes ao modo de vida e a micropolítica familiar dos grupos que estiverem mais envolvidos em sua formulação. Funciona portanto, como referente cultural fortíssimo na cidade, mesmo quando não é capaz de determinar sua forma final (ROLNIK, 1997: 13).

Por Fim, em Campo Grande, a gestão da urbanização foi instrumentalizada pelo Código de 1921 e norteada por uma cultura política marcada pela demolição do "velho", "feio" e "sujo" e pela construção ou substituição pelo "novo", "belo" e "higiênico". Os intendentes doutores objetivaram não apenas definir os espaços sociais, mas consolidar uma identidade progressista para a cidade, suficientemente capaz de diferenciar-se do norte de Mato Grosso - especialmente de Cuiabá -, considerado "inóspito", "atrasado" e “violento". Essas representações estão presentes no Álbum de Campo Grande de 1939, concebido como uma homenagem à cidade e à sua elite. O discurso celebrativo da identidade progressista do Sul de Mato Grosso em contraponto à região Norte, ainda nos dias atuais presentes nos discursos políticos e no imaginário dos sul-mato-grossenses, são questões para futuras pesquisas.

\section{Fontes}

CAMPO GRANDE (1937). Lei municipal n.24, de 02 de dezembro de 1937. São Paulo: Melhoramentos.

CÓDIGO DE POSTUAS de Desterro (1889). Código de Posturas da Câmara Municipal (aprovado pela Lei n. 1.238, de 22 de outubro de 1888). Desterro: Tipografia da Regeneração.

CÓDIGO DE POSTURAS de Campo Grande (1905). Campo Grande: Paço da Câmara Municipal da Villa de Campo Grande, 1905. ARCA: Revista de divulgação do Arquivo Histórico de Campo Grande (MS). Campo Grande, ARCA, n. 5, s/p., out. 1995.

CÓDIGO DE POSTURAS de Campo Grande (1921). Resolução no 43 de 21 de abril de 1921.

CONGRO, Rosário (1919). O Município de Campo Grande - 1919. Estado de Matto Grosso: Publicação Official .

GOMES, Arlindo de Andrade (1922). O Município de Campo Grande - 1921. Campo Grande: [s.n.]. 
INSTITUTO BRASILEIRO DE GEOGRAFIA E ESTATÍSTICA (IBGE) (1996). Conselho Nacional de Estatística. Evolução Demográfica dos Municípios de Mato Grosso do Sul segundo os Censos Demográficos Realizados e a Contagem. Brasília.

LEITÃO, Benedito (1939). Álbum de Campo Grande. Campo Grande: Tipografia O Progressista.

PROGRAMMA definitivo do Congresso de Engenharia e Indústria (1901). Revista do Club de Engenharia. Rio de Janeiro: Imprensa Nacional.

\section{Referências Bibliográficas}

ACHADO, Roberto (1978). Danação da norma: a medicina social e constituição da psiquiatria no Brasil.Rio de Janeiro: Edições Graal.

ANDRADE FILHO, Pérsio (2000). Série Campo Grande - personalidades. Campo Grande: Arquivo Histórico de Campo Grande.

ANDRADE, Rodrigo F. \& MAGALHÃES, Beatriz de A (1989). Um espaço para a República. Belo Horizonte: UFMG.

ARRUDA, Gilmar (1995). A Ferrovia Noroeste do Brasil: o último trem para o sertão. Caderno de Estudos Urbanos. Campo Grande, n. 03, s.p.

BRECIANNI, Maria Stella M (1998). História e hhistoriografia das cidades, um percurso. In: FREITAS, Marcos Cezar (Org.). Historiografia Brasileira em Perspectiva. São Paulo: Contexto.

CALDEIRA, Junia Marques (2007). A Praça Brasileira - trajetória de espaço urbano: origem e modernidade. Tese (Doutorado em História). Universidade Estadual de Campinas, Campinas, SP.

CARVALHO, José Murilo de (1997). Os bestializados: o Rio de Janeiro e a República que não foi. São Paulo: Companhia das Letras.

CHALHOUB. Sidney (1996). Cidade febril: cortiços e epidemias na corte imperial. São Paulo: Companhia das Letras.

DOI, José Evaldo de Mello; PAZIANI, Rodrigo Ribeiro \& CUELLO, Josué Peroni (2006). A saga de Ribeirão Preto na Belle Époque caipira: Modernidade e Urbanização na primeira República. Revista Dialogus, Ribeirão Preto, vol. 1, n.2, pp.135-160.

ELIAS, Norbert (1990). O Processo civilizador: uma história dos costumes. vol. 1. Rio de Janeiro: Jorge Zahar.

ENGELS, Frederich (1985). A situação da classe trabalhadora na Inglaterra. São Paulo: Global.

FOUCAULT, M (1987). Vigiar e punir. São Paulo, Vozes.

FREYRE, Gilberto (1998). Casa-Grande \& Senzala. Rio de Janeiro: Record.

GALETTI, Lylia S. G (2000). Nos confins da civilização: sertão, fronteira e identidade nas representações sobre Mato Grosso. São Paulo.Tese (Doutorado em História). Universidade de São Paulo, São Paulo.

GARDIN, Cleonice (1999). Campo Grande: entre o Sagrado e o Profano. Campo Grande: Ed. UFMS.

GOMES, William (2000). Dicionário cuiabanês. Cuiabá: [s.n.].

HOBSBAWM, Eric (1987). Mundos do trabalho: novos estudos sobre História operária. São Paulo: Paz e Terra.

LANNA, Ana Lúcia Duarte (1993). Uma cidade na transição: Santos: 1870-1913. Santos: HUCITEC. 
LEAL, Victor Nunes (1948). Coronelismo, enxada e voto. Rio de Janeiro: Forense.

LOBATO, Monteiro (2003). Aventuras no Sítio do Pica-Pau Amarelo. Tia Anastácia e o Folclore. São Paulo: Globo.

MACHADO, Paulo Coelho (1991). A Rua Barão. Série Pelas Ruas de Campo Grande, vol. 1. Campo Grande: Tribunal de Justiça de Mato Grosso do Sul.

(2000). Pelas ruas de Campo Grande: a Grande Avenida. Campo Grande: Gráfica Brasília.

MAIA, Clarissa Nunes (2001). Policiados: controle e disciplina das classes populares na cidade do Recife, 1865-1915.Tese (Doutorado em História). Universidade Federal de Pernambuco, Recife.

NETO, José Miguel Arias (2003). Primeira República: economia cafeeira, urbanização e industrialização. In: DELGADO, Lucilia de Almeida Neves \& FERREIRA, Jorge (Orgs.). O Brasil Republicano: O tempo do liberalismo excludente. Da Proclamação da República à Revolução de 1930. Rio de Janeiro: Civilização Brasileira, pp. 191-230.

OLIVEIRA NETO, Antônio Firmino de (2003). Campo Grande e a rua 14 de Julho.Tese (Doutorado em Geografia). Universidade Estadual Paulista "Júlio Mesquita Filho", Presidente Prudente, SP.

PEREIRA, Armando de Arruda (1928). No sul de Matto Grosso (conferência). 21.05.1928.

PESTANA, Lucas Tjhio Cesar; ALVES, Flávio Macedo \& SARTORI, Ângela Lúcia Bagnatori (2011). Espécies arbóreas da arborização urbana do centro do município de Campo Grande, Mato Grosso do Sul, Brasil. REVSBAU, Piracicaba - SP, vol.6, n.3

RIBEIRO, Lélia Rita Euterpe de Figueiredo (1993). O homem e a terra. Campo Grande: IHGMS.

ROLNIK, Raquel (1997). A cidade e a lei: legislação, política urbana e territórios na cidade de São Paulo. São Paulo: FAPESP/Studio Nobel.

SAMPAIO, Consuelo Novais (1975). Os partidos políticos da Bahia na Primeira República: uma política de acomodação. Salvador: Centro Editorial e Didático Universidade Federal da Bahia.

SANTOS, Eunice Ribeiro dos (2011). Fotojornalismo como fonte histórica: contribuições da comunicação para a produção historiográfica. Revista Tempo de Histórias. Publicação do Programa de Pós-Graduação em História da Universidade de Brasília PPG-HIS, n. 18, Brasília, jan/jul.

SANTOS, Henrique Sena dos (2012). "Pugnas Renhidas": futebol, cultura e sociedade em Salvador (1901-1924). Dissertação (Mestrado em História). Universidade Estadual de Feira de Santana,Feira de Santana, BA.

SANTOS, Roberto Carlos dos (2002).Urbanização, moral e bons costumes: Vertigens da Modernidade em Patos de Minas: 1900/1960. Dissertação (Mestrado em História). Universidade Federal de Uberlândia,Uberlândia, MG.

SCHWARCZ, Lilia Moritz (1993). O espetáculo das raças. Cientistas, instituições e questão racial no Brasil, 1870-1930. São Paulo: Companhia das Letras.

SELBACH, Jeferson Francisco (2009). Mobilidade urbana nos códigos de posturas de São Luis/MA. In: ALCÂNTARA JÚNIOR, José O. \&SELBACH, Jeferson Francisco (Orgs) Mobilidade urbana em São Luis. São Luís: EdUFMA.

SERRA, Ulisses (1989). Camalotes e Guavirais. 2 ed. Campo Grande: Tribunal de Justiça de Mato Grosso do Sul.

SEVCENKO, Nicolau (1983). Literatura como missão: tensões sociais e criação cultural na Primeira República.São Paulo: Brasiliense. 
(1994). Futebol, metrópoles e desatinos. Revista USP. São Paulo, n. 22, pp. 30-37, jun./jul./ago.

SILVA, Mozart Linhares da (1997). Do império da lei às grades da cidade. Porto Alegre: EdiPUCRS.

TAVEIRA, Eduardo \& HIGUCHI, Maria Inês Gasparetto (2011). Políticas públicas de proteção ambiental no espaço urbano e o colorido das implicações socioeducativas na criação do parque municipal nascentes do Mindu. Revista Estudos Universitários. Sorocaba, SP, vol. 37, n. 1, pp. 51-74, jun.

THOMPSON, Edward P (1998). Costumes em comum. São Paulo: Companhia das Letras. VIOTTI da COSTA, Emilia (1994). Da Monarquia à República: momentos decisivos. São Paulo: Brasiliense.

Artigo recebido em 04 de agosto de 2015.

Aprovado em 19 de outubro de 2015.

DOI: 10.12957/intellectus.2015.20984 